\title{
Implementation of Parallel Synchronization Method of Generators for Power \& Cost Saving in University of Gujrat
}

\author{
Uzma Amin, Ghulam Ahmad, Sumbal Zahoor, Fariha Durrani \\ Electrical Engineering Department, Faculty of Engineering, University of South Asia, Lahore, Pakistan \\ Email: uzma.amin@usa.edu.pk
}

Received 28 July 2014; revised 12 August 2014; accepted 20 August 2014

Copyright (C) 2014 by authors and Scientific Research Publishing Inc.

This work is licensed under the Creative Commons Attribution International License (CC BY).

http://creativecommons.org/licenses/by/4.0/

(c) (i) Open Access

\begin{abstract}
In the current economic and political scenario of Pakistan where new projects of Electrical generation seems impossible, one should adopt such means so as to minimize the power consumption via load management. In this paper a relatively better Electrical power system is proposed for University of Gujrat (UOG) power system. UOG runs its all generators whether it is full load or merely a load of 20 percent as a standby power. It is suggested that if generators system is synchronized and connected in parallel, it can not only minimize the cost, number of personnel required but also increase the reliability of the system. ETAP software is used for simulation and results show that by adopting this method generation cost can be reduced up to 30 percent which is indeed a huge figure. Losses and cable parameters were calculated using this software and found this proposal quite feasible.
\end{abstract}

\section{Keywords}

Synchronization, Load Management, Reliability, Cable, Transformer

\section{Introduction}

Today Pakistan is facing disastrous power crises. The demand is much higher than supply so energy supplied to consumers is not continuous and load shedding of 12 - 16 hours badly affects the consumers. The University of Gujrat (UOG) is also affected by this load shedding, to carry on educational activities without any interruption; University of Gujrat has its own standby power system. In UOG for every one or two blocks there is a separate generator. These generators run on almost $30 \%$ or less load in 10 months of the year and run on almost $50 \%$ load in remaining two months i.e. May and June. In case if any of the generators becomes out of order, the relevant 
block faces total black out. So to provide continuous supply to all of the blocks, it is better to operate generators in parallel (synchronized generators operation). In this way if any of the generators goes out of order, the blocks will still avail electricity supply from parallel connected generators. This is the main idea of this research work.

UOG is facing financial losses in aspect of standby power system. These losses comprise of fuel cost, higher maintenance cost and lubrication oil cost. Therefore by implementing this method, these losses can be reduced to a great extent. Furthermore UOG can also avail many advantages of this configuration like a lot of savings in terms of diesel cost. For example in synchronized operation of generators, there may be a need to run only two generators instead of three or four, hence fuel and maintenance cost is reduced.

Heavy load of blocks for example machinery, medical lab equipment, and other such sort of massive loads can be operated easily by parallel synchronization method because all the generators are synchronized and bulk load can be managed. But in existing system to operate such load, a separate generator has to install as it is done in Medical Block in recent months. Synchronized generators method also has the ability to meet future expansion of the load. For example, if all the blocks have to build a new computer lab in future then to meet this demand, there is a need to install a single generator in parallel. But if generators are not synchronized, we have to install a generator for all of the blocks instead of one. In parallel operation of generators efficiency of the system will be improved. Less number of personnel is required [1].

\section{Power System of UOG}

\subsection{Transformers}

The power entering into the UOG power system is distributed using distribution transformers of different KVA ratings. These transformers step down the voltage from $11 \mathrm{kV}$ to 400 volts line to line. There are a total of about 36 transformers of total $4700 \mathrm{kVA}$. Their number and kVA ratings, the location of each transformer with the load it is serving, the current output of each transformer and the voltage at each of them given in Table 1.

\section{Table 1. Transformers location and rating.}

\begin{tabular}{|c|c|c|}
\hline Sr \# & Location & KVA rating \\
\hline 1 & E Block & 200 \\
\hline 2 & M Block & 200 \\
\hline 3 & A Block & 200 \\
\hline 4 & B Block & 200 \\
\hline 5 & S Block & 200 \\
\hline 6 & P Block & 200 \\
\hline 7 & BS Block & 200 \\
\hline 8 & Guest House & 200 \\
\hline 9 & Admin Block & 200 \\
\hline 10 & Durbar & 100 \\
\hline 11 & Water Turbine & 200 \\
\hline 12 & Girls Hostel 1 & 200 \\
\hline 12 & Girls Hostel 2 & 200 \\
\hline 14 & Mosque & 200 \\
\hline 15 & Lane 1 Residences & 200 \\
\hline 16 & Lane 2 Residences & 200 \\
\hline 17 & Lane 3 Residences & 200 \\
\hline 18 & Main Gate & 200 \\
\hline 19 & Boys Hostel 1 & 200 \\
\hline 20 & Boys Hostel 2 & 200 \\
\hline 21 & SSIC & 200 \\
\hline 22 & IR & 200 \\
\hline 23 & IHRM & 200 \\
\hline \multirow[t]{2}{*}{24} & SSC & 200 \\
\hline & TOTAL & 4700 \\
\hline
\end{tabular}




\subsection{Generators}

The power input source of UOG is behind the main gate of the university, which is provided by WAPDA. It also has thirteen mobile diesel operated generator sets of different capacity. All these generator sets are made by SMJ company. The generation voltage of these generators sets is $380 \mathrm{~V}$, which is directly fed to the different department of UOG. Location and kVA rating of these generators is shown in Table 2.

\section{What Is Synchronization}

In today's world of technology, a separate generator is found very rare supplying the load independently. Very often on small places where the emergency power is required for a short while the synchronous generator is used independently. As in any Electrical system, the loads are not constant load is varying with time, Electrical systems are interconnection of large number of alternators operating in parallel and supplying large number of loads. During the process of synchronization of generators the magnitude of voltage, frequency and phase angle is kept constant this process of paralleling of one alternator to another or to the bus bar is called the synchronization. Figure 1 shows the block diagram of the synchronized system, where three generators are connected to the same load and any time these can be used together to address the load demand [2].

\subsection{Need of Synchronization}

In any power system it is preferred that instead of supplying power with one big unit, use one or more units at

Table 2. Generators location and rating.

\begin{tabular}{|c|c|c|}
\hline Sr \# & Location & KVA rating \\
\hline 1 & $\mathrm{E}+\mathrm{M}$ Block & 200 \\
\hline 2 & $\mathrm{~A}+\mathrm{B}$ Block & 200 \\
\hline 3 & S Block & 150 \\
\hline 4 & $\mathrm{P}+\mathrm{BS}$ Block & 200 \\
\hline 5 & Guest House & 20 \\
\hline 6 & Admin Block & 100 \\
\hline 7 & Water Turbine & 100 \\
\hline 8 & Girls Hostel 1 + Female Faculty & 50 \\
\hline 9 & Girls Hostel $2+$ Mosque & 30 \\
\hline 10 & VC House & 20 \\
\hline 11 & Residence & 100 \\
\hline 11 & Movable (1) & 110 \\
\hline 12 & Movable (2) & 20 \\
\hline 13 & Boys Hostel & 50 \\
\hline 14 & SSIC & 100 \\
\hline \multirow[t]{2}{*}{15} & IHRM \& SSC & 50 \\
\hline & TOTAL & 1500 \\
\hline
\end{tabular}

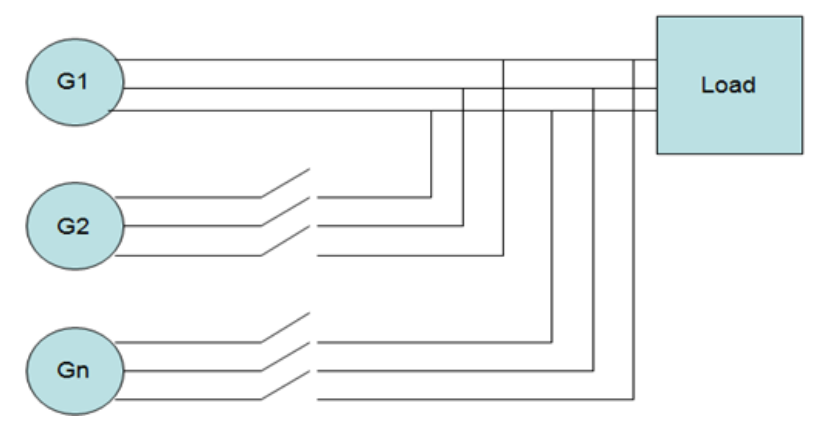

Figure 1. Synchronization. 
different load conditions, there are number of benefits that are given below when we run alternators in parallel.

1) As we know the efficiency of any machine is maximum at its full load and we can run any machine when it is required and doing this efficiency can be increased.

2) Using several generators can supply a bigger load.

3) Reliability of the system is increased since if one generator is failed than the other is used for the operation and whole system will not be shut down.

4) Having many generators that are working in parallel we can remove one or more generator for the maintenance purpose.

5) If load demand increases than more generators can be connected.

6) Instead of placing generators at different locations it is better to place all of them at one place it will ease the maintenance.

7) Standby losses and per unit price is reduced because our generation is according to our demand [3].

\subsection{Conditions for Synchronization}

The conditions for the generators to be paralleled are given below:

1) The RMS value new coming generator voltage should be equal to the bus bar voltage.

2) The phase sequence of new coming generator should be same to that of bus bar. The phase angle must be the same.

3) The frequency of new generator called the incoming frequency of the generator should be slightly higher than that of running frequency of the bus bar.

The first condition can be found by using the volt meter and the second and $3^{\text {rd }}$ can be found by using lamp method or Synchroscope [4].

\subsection{Techniques for Synchronization}

Different techniques are being used for the synchronization of the alternators, the purpose is to check the all four conditions listed above and then different schemes are used to connect the generators to the system. These methods are given below:

1) The bright lamp method.

2) The dark lamp method.

3) The Synchroscope method.

These methods are not preferred today due to less accuracy and manual operation; these methods required a very experienced person and also reliability and security of these methods is not enough. So, Synchroscope method is used now a day and microprocessor based systems are used for the automatic synchronization of the alternators, these methods are reliable and easier to manage [5].

\subsection{Synchronization Using Synchroscope}

As it is already being explained that for synchronization the lamp method is not applicable because it depends on operator decision and experience. And although the three lamp method is cheap but it cannot tell us that either the frequency of incoming generator is higher or lower, in order to parallel alternators in right way a device named Synchroscope is used. In larger systems lamp method is not applicable so Synchroscope method is used. It consists of three coils and one moving vane. A pointer is connected to moving vane. The coils are connected to the bus bar and the alternator which is to be synchronized. The potential transformer is used to measure the voltage difference, the pointer move in clockwise and antic clockwise manner and when speed of incoming machine is same to that of bus bar then pointer will stop at vertical point and relays are closed that connect the alternator to the bus bar as shown below in Figure 2. Assume the voltage difference, the pointer move in clockwise or anti clockwise manner and when speed of incoming machine is same to that of bus.

If the phase angle between the two voltages is different than the pointer of Synchroscope will move, it will move to slower point when the incoming machine is slower and move towards the faster point if then incoming machine is faster and pointer will stop when the incoming generator frequency is same to that of bus bar if this situation is attained then the switch is closed [5]. 


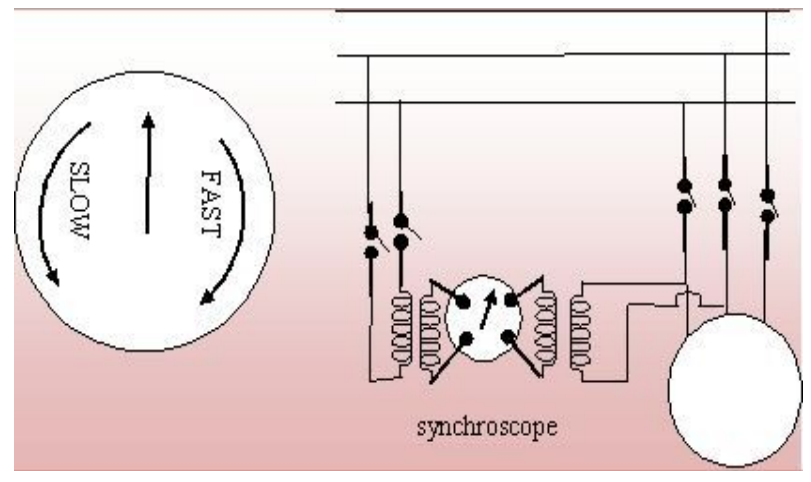

Figure 2. Schematic diagram of Synchroscope.

\section{Existing System of UOG and Its Drawbacks}

\subsection{Power Requirement of UOG}

Annual power required for UOG is increasing day by day; energy requirement for UOG from year 2009 to 2013 and expected increase in energy demand after 2013 is given in Table 3.

\subsection{Prime Power}

As the energy crisis in Pakistan is almost at its peak, approximately there is 12 - 16 hours of load shedding per day. So that's why the prime power supplied by the electric company is almost $30 \%-40 \%$. Due to this severe problem, UOG requires a lot of stand by energy to fulfill out electricity requirements. In the compensation of this problem UOG is using generators to accomplish their stand by power. The per unit cost of electricity is given below:

Present cost of WAPDA/Kwhr (Unit) = 13 Rs./Kwhr [6].

\subsection{Standlby Power}

In order to fulfill the standby power requirements, UOG is using number of generators at different locations. Per unit cost of stand by generators are: Cost of unit produced by diesel generator/Kwh (Unit) $=33 \mathrm{Rs} . / \mathrm{Kwhr}$. The total generation capacity of these generators is $1500 \mathrm{KVA}$.

\section{Drawbacks of Existing System}

\subsection{No Reliability}

For every system reliability is one the most important factor. It means supply of energy should be consistently available at any time. The current system is not reliable as it should be. For example academic blocks are fed by separate generators and in case of maintenance issue or if any generator is out of order for a time, the respected block is black out, and the minimum maintenance time for a generator is at least one day, it means the respected block should remain without electricity for a long time.

One another example is of the generator which is installed for water pump is of $100 \mathrm{kVA}$, if this generator is out of order the water supply for the entire university is disturbed, on the same time all the generators are running properly and generating extra electricity which is not entertained. According to current system there are blocks which are fed by a generator of high kVA rating which is large enough to entertain two blocks at once. In case one generator for a block is out of order and at the same time the generator of adjacent block generates enough electricity which could entertain both the blocks, but the current system does not allow doing so.

\subsection{Higher Cost}

For any engineering system lower cost and maximum output is always preferred, so first and foremost priority for an engineer is to reduce the cost of the system. As in existing case numbers of circumstances are available when load requirement is less to an extent that one or two generators are enough to meet the demand of aca- 
Table 3. Power requirement of UOG.

\begin{tabular}{lc}
\hline Year & Power requirement \\
2008 & $300 \mathrm{KVA}$ \\
2009 & $600 \mathrm{KVA}$ \\
2010 & $800 \mathrm{KVA}$ \\
2011 & $1000 \mathrm{KVA}$ \\
2012 & $1150 \mathrm{KVA}$ \\
2013 & $1200-1250 \mathrm{KVA}$ \\
2014 & $1300-1400$ KVA (Expected) \\
\hline
\end{tabular}

demic blocks. For example in winter season and after 4 PM. the total demand of the academic blocks is reduced to $25 \%$ of the peak demand, it could be fed by one generator and separate generator for each block is not required. But use of all generators as in the case of existing system to provide the electricity increases the cost in terms of diesel and maintenance requirement.

\subsection{Less Efficiency}

Efficiency is one of the most important factor of the system. Smaller input and greater output is the first preference. A more efficient system provides more stability and reduces cost and losses. In UOG all of the generators are running at $25 \%$ - $50 \%$ of the maximum load. The optimal operational point for synchronous generator is $75 \%$ - $80 \%$ load of its rated value. At this optimal point the synchronous generator will be at its maximum efficiency. At evening the generators are operated at $25 \%$ of the load in order to reduce diesel cost, its mean generators are operating at lower efficiency that is not good for the life of the generator. Using one generator running at $80 \%$ of the load will increase the efficiency of the system and reduces the fuel and maintenance cost as well [7] [8].

\subsection{No Future Extension}

An Electrical system is designed in such a manner to provide electricity for the loads introducing in future. This increases the reliability of that system. If a system is designed according to the prescribed condition it will be long lasting. It is noticed that electricity demand is increasing annually in UOG so in case of future expansion same generators will not be able to feed the system. For this compensation there is requirement to install new generators or replace the existing one by a higher kVA value, but both of the things are difficult to evaluate.

\subsection{Annual Diesel Cost of Existing Generators}

Annual costs of diesel generators have been calculated. Calculations were shown in Table 4.

Total diesel cost per year is Rs. 3,780,100/—excluding lubrication cost.

\section{Fuel Cost Comparison for Existing \& Proposed System}

In this section calculations were done for the fuel cost of various months and the savings obtained by connecting the generators in parallel combination (Synchronization). For these calculations an average of 5 - 6 hour load shading is taken into account. Fuel cost and savings in the month of March is given below in Tables 5-7.

\section{Fuel Cost Comparison in Month of March}

Avg load at Generator 1 per day $=42.66 \mathrm{kVA}$.

Avg load at Generator 2 per day $=41.86 \mathrm{kVA}$.

Avg load at Generator 3 per day $=26.91 \mathrm{kVA}$.

Avg load at Generator 4 per day $=40.70 \mathrm{kVA}$.

So savings in the month of March is = Rs. 441,575.

Similarly calculations were done for the months of April, May, June and July. Saving for these months are rupees respectively. 
Table 4. Diesel cost of existing generators.

\begin{tabular}{cccccc}
\hline Location & Capacity & $\begin{array}{c}\text { Fuel consumption } \\
\text { Ltr/hr }\end{array}$ & $\begin{array}{c}\text { Average running } \\
\text { hours/month }\end{array}$ & Diesel drawn/month & Cost Rs./month \\
\hline E + M Block & 200 & 26 & $80-90$ & 2210 & 221,000 \\
A + B Block & 200 & 26 & $80-90$ & 2210 & 221,000 \\
S Block & 150 & 19 & $80-90$ & 1615 & 161,500 \\
P + BS Block & 200 & 26 & $80-90$ & 2210 & 221,000 \\
Admin Block & 100 & 15 & $150-160$ & 2325 & 232,500 \\
SSIC & 100 & 15 & $80-90$ & 1275 & 127,500 \\
Water Turbine & 100 & 15 & $70-75$ & 1050 & 105,000 \\
Mosque Girls Hostel & 30 & 05 & $150-260$ & 900 & 90,000 \\
VC House & 20 & 04 & $190-200$ & 760 & 76,000 \\
Boys Hostel & 50 & 12 & $150-160$ & 1800 & 180,000 \\
Girls + Faculty Hostel & 50 & 12 & $150-160$ & 1800 & 180,000 \\
Residences & 100 & 15 & $140-150$ & 2250 & 225,000 \\
Guest House & 20 & 04 & $130-140$ & 520 & 52,000 \\
Moveable 1 & 110 & 16 & $50-60$ & 880 & 88,000 \\
Moveable 2 & 20 & 04 & $50-60$ & 200 & 20,000 \\
IHRM \& SSC & 50 & 12 & $40-50$ & 540 & 54,000 \\
TOTAL & 1400 & & & $3,708,100$ \\
\hline
\end{tabular}

Table 5. Generators operating at 25\% load.

\begin{tabular}{cccccc}
\hline Generator & $\begin{array}{c}\text { Avg load/day } \\
\text { (KVA) }\end{array}$ & $\begin{array}{c}\text { Fuel drew } \\
\text { (Ltr/hr) }\end{array}$ & $\begin{array}{c}\text { Running hours } \\
\text { in a month }\end{array}$ & $\begin{array}{c}\text { Fuel consumed } \\
\text { (Ltr) }\end{array}$ & $\begin{array}{c}\text { Cost per } \\
\text { month (Rs.) }\end{array}$ \\
\hline G1 & 42.66 & 12.5 & 85 & 1079.5 & 107,900 \\
G2 & 41.86 & 12.5 & 85 & 1079.5 & 107,900 \\
G3 & 26.91 & 09 & 85 & 765.5 & 76,500 \\
G4 & 40.70 & 12.5 & 85 & 1079.5 & 107,900 \\
Total & 152.3 & 45.5 & 340 & 4003.5 & 400,200 \\
\hline
\end{tabular}

Table 6. Generators operating at 50\% load.

\begin{tabular}{cccccc}
\hline Generator & $\begin{array}{c}\text { Avg load/day } \\
\text { (KVA) }\end{array}$ & $\begin{array}{c}\text { Fuel drew } \\
(\text { Ltr/hr) }\end{array}$ & $\begin{array}{c}\text { Running hours } \\
\text { in a month }\end{array}$ & $\begin{array}{c}\text { Fuel consumed } \\
\text { (Ltr) }\end{array}$ \\
\hline G1 & 42.66 & 25 & 85 & 2125 & 212,500 \\
G2 & 41.86 & 25 & 85 & 2125 & 212,500 \\
G3 & 26.91 & 17 & 85 & 1445 & 2125 \\
G4 & 40.70 & 25 & 85 & 340 & 7820 \\
Total & 152.3 & 92 & & 760,325 \\
\hline
\end{tabular}

Table 7. Generators operating at $80 \%$ load.

\begin{tabular}{cccccc}
\hline Generator & $\begin{array}{c}\text { Avg load/day } \\
\text { (KVA) }\end{array}$ & $\begin{array}{c}\text { Fuel drew } \\
\text { (Ltr/hr) }\end{array}$ & $\begin{array}{c}\text { Running hours } \\
\text { In a month }\end{array}$ & $\begin{array}{c}\text { Fuel consumed } \\
\text { (Ltr) }\end{array}$ & 3187.5 \\
\hline 200 KVA & 152.3 & 37.5 & 85 & 318750 \\
\hline
\end{tabular}

\section{Real Time Reading of Generators}

\section{Generators Reading in Different Months}

Several real time readings were taken from the Generators in different months at different times using clamp meter and load of each generator is calculated. The readings of all four generators at different times are given in Tables 8-11 at different times and days. 
Table 8. Generators reading in March.

\begin{tabular}{|c|c|c|c|c|c|c|c|}
\hline & \multicolumn{3}{|c|}{ Date: $15-03-2013$} & \multicolumn{2}{|c|}{ Time: 04:50 PM } & \multirow[b]{2}{*}{ P Block } & \multirow[b]{2}{*}{ BS Block } \\
\hline & E Block & M Block & A Block & B Block & S Block & & \\
\hline R (Phase) & 19 & 10 & 14 & 04 & 20 & 09 & 20 \\
\hline Y (Phase) & 08 & 06 & 16 & 06 & 11 & 10 & 08 \\
\hline B (Phase) & 32 & 22 & 17 & 16 & 19 & 08 & 14 \\
\hline S (KVA) & 13.62 & 8.77 & 10.85 & 6.00 & 11.54 & 6.23 & 9.69 \\
\hline ST (KVA) & & & & 66.74 & & & \\
\hline
\end{tabular}

Table 9. Generators reading in April.

\begin{tabular}{|c|c|c|c|c|c|c|c|}
\hline & & & $10-04-2013$ & Time: 2:00 PM & & & \\
\hline & E Block & M Block & A Block & B Block & S Block & P Block & BS Block \\
\hline R (Phase) & 59.7 & 23 & 46 & 22.8 & 22 & 41 & 82 \\
\hline Y (Phase) & 25 & 25 & 55 & 36.3 & 19 & 26 & 40 \\
\hline B (Phase) & 71 & 22 & 42 & 43.8 & 56 & 28 & 58 \\
\hline $\mathrm{S}$ (KVA) & 35.95 & 16.19 & 33.02 & 23.76 & 22.40 & 21.93 & 41.56 \\
\hline ST (KVA) & & & & 194.82 & & & \\
\hline
\end{tabular}

Table 10. Generators reading in May.

\begin{tabular}{|c|c|c|c|c|c|c|c|}
\hline \multicolumn{8}{|c|}{ Date: 17-05-2013 } \\
\hline & E Block & M Block & A Block & B Block & S Block & P Block & BS Block \\
\hline R (Phase) & 60 & 91 & 82 & 60 & 61 & 108 & 53 \\
\hline Y (Phase) & 73 & 56 & 80 & 90 & 42 & 90 & 51 \\
\hline B (Phase) & 54 & 79 & 86.3 & 71.7 & 95 & 96 & 85 \\
\hline $\mathrm{S}$ (KVA) & 43.18 & 52.19 & 57.34 & 51.19 & 45.72 & 67.89 & 43.64 \\
\hline ST (KVA) & & & & 361.19 & & & \\
\hline
\end{tabular}

Table 11. Generators reading in June.

\begin{tabular}{|c|c|c|c|c|c|c|c|}
\hline \multicolumn{8}{|c|}{ Date: 13-06-2013 } \\
\hline & E Block & M Block & A Block & B Block & S Block & P Block & BS Block \\
\hline R (Phase) & 51 & 76 & 41 & 53 & 93 & 95 & 85 \\
\hline Y (Phase) & 49 & 51 & 43 & 104 & 89 & 75 & 65 \\
\hline B (Phase) & 78 & 69 & 42 & 95 & 129 & 98 & 62 \\
\hline $\mathrm{S}$ (KVA) & 41.10 & 45.26 & 29.09 & 58.19 & 71.82 & 61.89 & 48.95 \\
\hline ST (KVA) & & & & 356.33 & & & \\
\hline
\end{tabular}

\section{E-Tap Simulations}

Using previous mentioned readings of loads two E-Tap models one for synchronized system and for un-synchronized system were made for the power system of UOG. In these models real time values of load were used. The ETAP Load Flow Analysis module calculates the bus voltages, branch power factors, currents, and power flows, throughout the Electrical system. Newton Raphson method is adopted to find the optimum results and five iterations were required for this method. Following are the equations used in Newton Raphson calculations.

$$
V_{\rho}=\left|V_{\rho}\right|<\delta_{\rho}=e_{\rho}+j f_{\rho}
$$

$e_{\rho}$ and $j f_{\rho}$ are real and imaginary parts of voltage in Equation (1).

$$
\begin{aligned}
P_{i} & =U_{1}(e, f) \\
Q_{i} & =U_{2}(e, f)
\end{aligned}
$$


$\delta$ is the phase angle and $P_{i}$ and $Q_{i}$ denotes the real and active power in Equations (1), (2) and (3) respectively.

$$
\begin{gathered}
\Delta P_{i}=\sum_{p=2}^{n} \frac{\partial P_{i}}{\partial e_{p}} \Delta e_{p}+\sum_{p=2}^{n} \frac{\partial P_{i}}{\partial f_{p}} \Delta f_{p} \\
\Delta Q_{i}=\sum_{p=2}^{n} \frac{\partial Q_{i}}{\partial e_{p}} \Delta e_{p}+\sum_{p=2}^{n} \frac{\partial Q_{i}}{\partial f_{p}} \Delta f_{p}
\end{gathered}
$$

Active and reactive power mismatch can be calculated from Equations (4) and (5) respectively.

$$
\begin{gathered}
{\left[\frac{\Delta P}{\Delta Q}\right]=\left[\frac{J_{1} \mid J_{2}}{J_{3} \mid J_{4}}\right] \cdot\left[\frac{\Delta e}{\Delta f}\right]} \\
\left|V_{i}\right|^{2}=e_{i}^{2}+f_{i}^{2}
\end{gathered}
$$

Voltage is the sum of square of real and imaginary parts of voltage and can be calculated using Equation (7).

$$
\Delta\left|V_{i}\right|^{2}=\frac{\partial\left|V_{i}\right|^{2}}{\partial e_{i}} \Delta e_{i}+\frac{\partial\left|V_{i}\right|^{2}}{\partial f_{i}} \Delta f_{i}
$$

Voltage mismatch can be calculated using Equation (8).

\subsection{Un-Synchronized System Simulation}

In un-synchronized system all the generators are working separately at different locations in UOG. There are four generators for seven academic blocks. First generator feds Engineering and Medical Block, second generator feds Academic and Business Blocks, third generator feds Science Block, while the fourth generator feds $\mathrm{P}$ and BS Blocks. Real time readings of load in E-Tap were used to take the load flow calculation. E-Tap model for un-synchronized system and load flow report shown in Figure 3 and Figure 4 respectively.
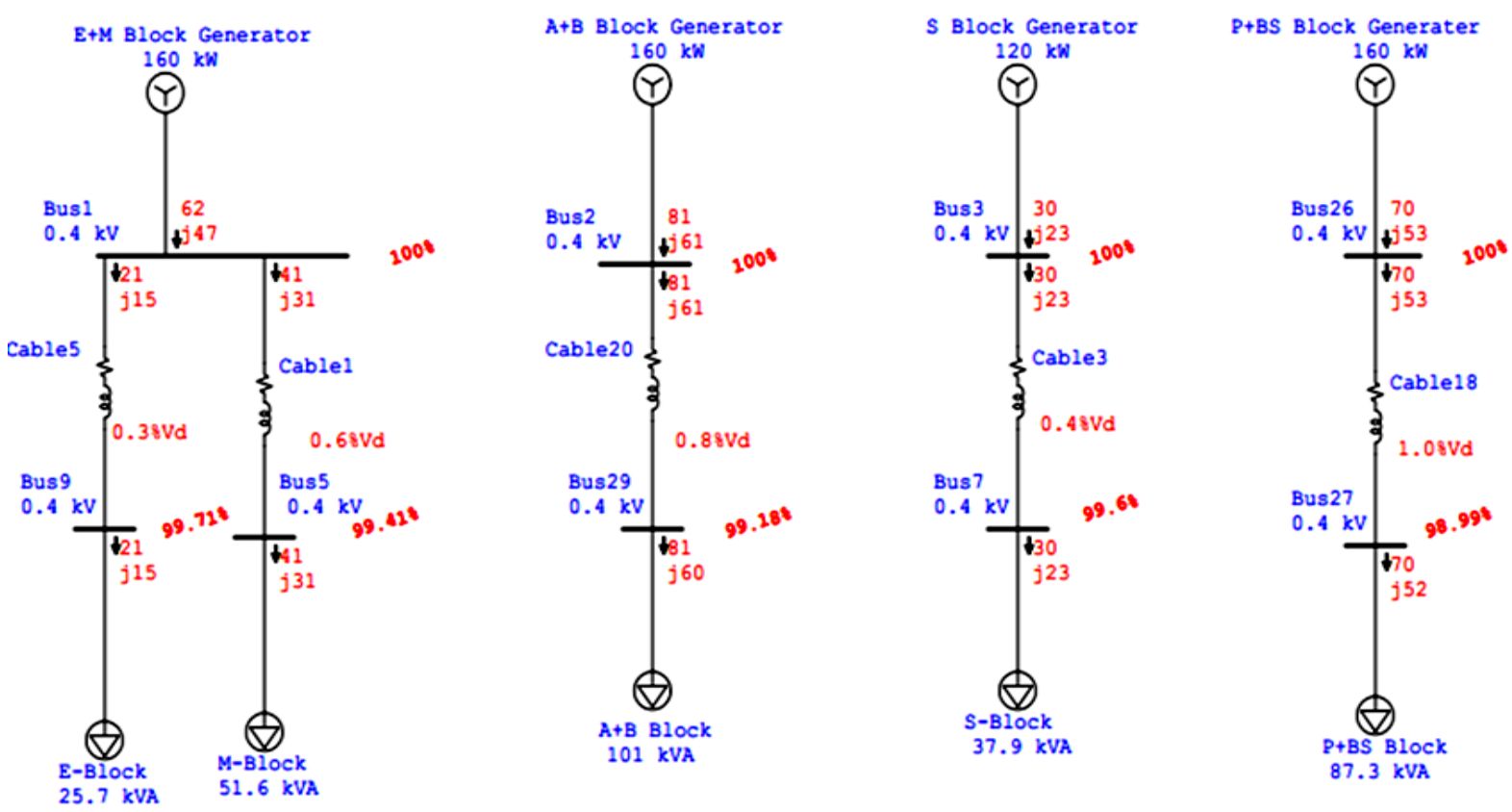


\begin{tabular}{lcll} 
Project: & ETAP & Page: & 1 \\
Location: & 6.00 & Date: & $05-29-2013$ \\
Contract: & & SN: & 12345678 \\
Engineer: & StudyCare: LF & Revision: Base \\
Filename: & & Configect & Normal \\
\hline
\end{tabular}

Existing System (Unsynchronized) Date: 12-04-13 Time: 11:30 AM

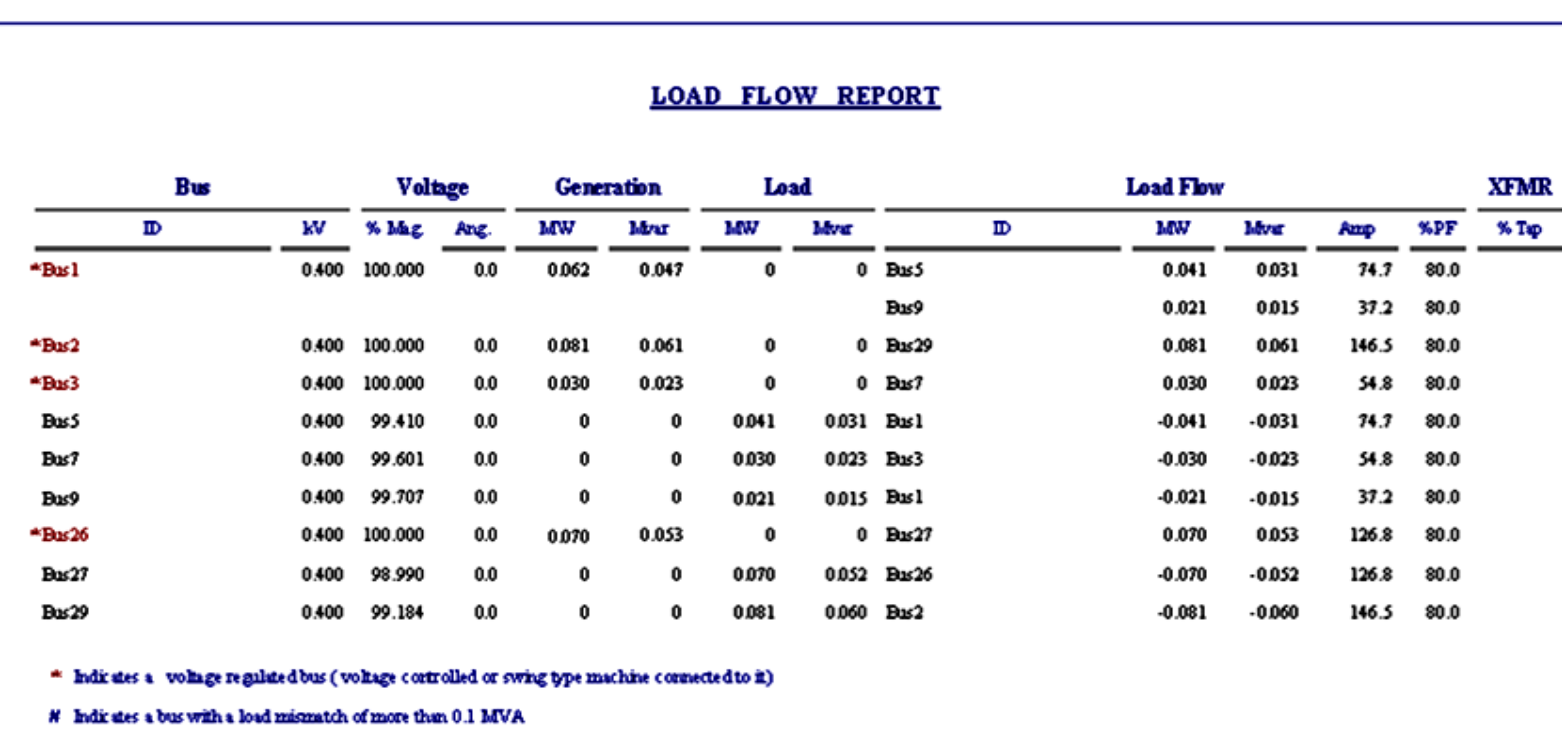

Figure 4. Load flow report.

\subsection{Synchronized System Simulation}

In synchronized system which is the proposed solution, all the generators are connected in parallel and then load flow calculations are performed on this system. In this system all the generators give supply to a main bus bar, and then different cables execute from this bus bar and reach the academic blocks. The E-Tap models include two different schemes, i.e. once using aluminum conductor and once using copper conductor. E-Tap model \& load flow report for aluminum and copper conductor have been shown in Figures 5-8.

\section{Synchronized Generator Operation}

For this solution all the generators for the academic blocks have to be placed on one place then they will be synchronized through a synchronization panel. In this manner all the generators will supply power on a bus bar. Academic blocks will get supply from this common bus bar through cables of different gauge depending upon the respective load. Generators will get start according to the load demand, for example if load of all the blocks is $300 \mathrm{KVA}$, then only two generators of $200 \mathrm{KVA}$ and $150 \mathrm{KVA}$ will run to meet this demand. In this manner only two generators are required for the total demand instead of four generators as present. In winter season for reduced load only one generator is enough to meet the load demand. This solution will result in minimum cost.

The diagrammatic representation of our proposed solution is given in Figure 9. In this figure the cables which are shown in bold are pre-installed, while the cables shown in light lines are to be installed. The length and gauge of all the cables have been shown. Cable of gauge $400 \mathrm{~mm}^{2}$ which is to be installed has a length of 200 meters, while the cable of gauge $240 \mathrm{~mm}^{2}$ has a length of 135 meters.

\subsection{Existing Equipments}

1) Four Generators (200 kVA * $3+150 \mathrm{kVA} * 1)=750 \mathrm{KVA}$.

2) ATS switches.

3) Bus bars. 


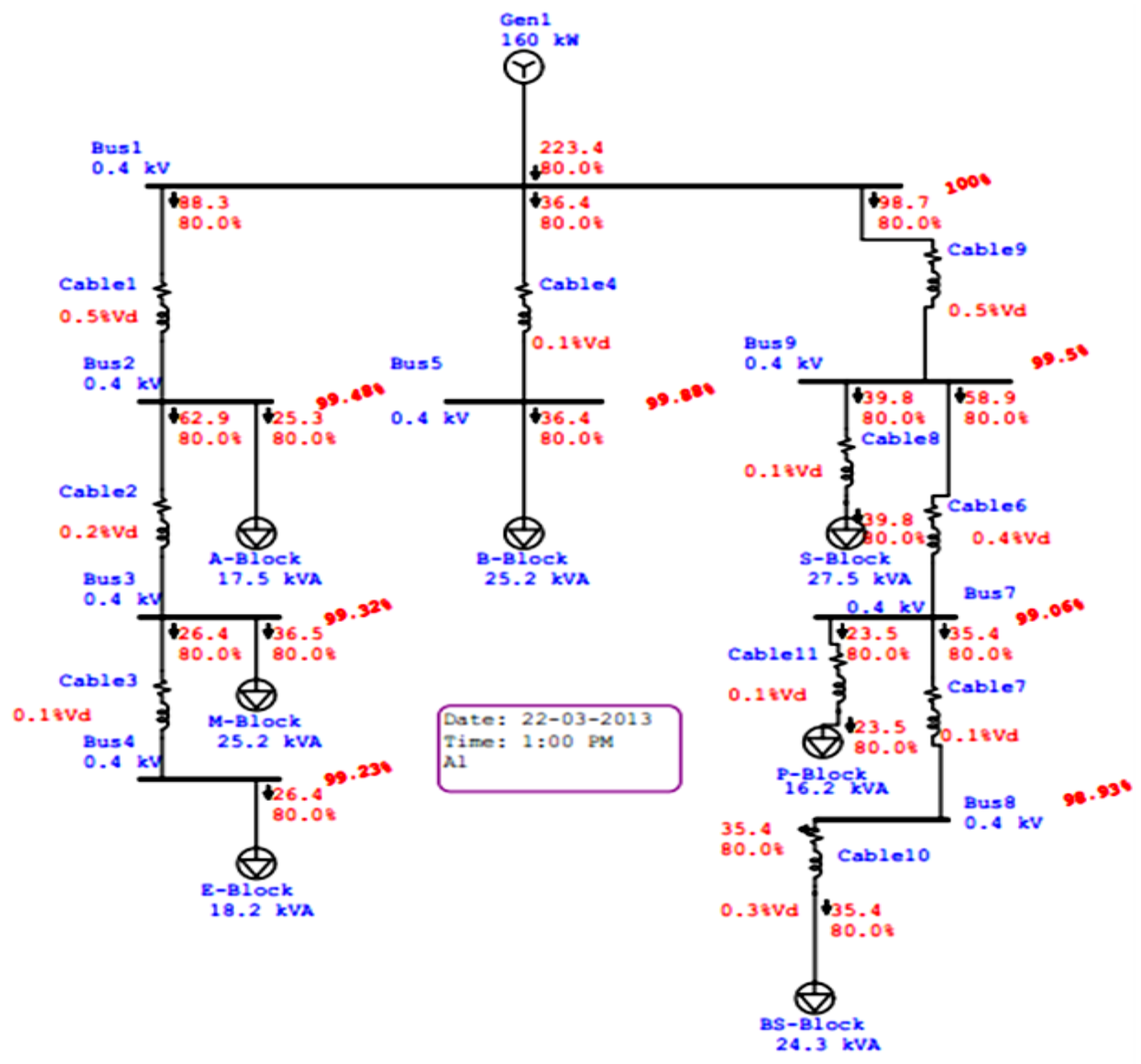

Figure 5. E-TAP model with aluminum conductor.

\subsection{Equipment Required for Proposed Solution}

1) Synchronization panel.

2) Cables of gauge $240 \mathrm{~mm}^{2}$ and $400 \mathrm{~mm}^{2}$ to be installed.

3) ATS switches.

4) Generators to be synchronized.

5) Main bus bar.

6) Circuit breakers.

\subsection{Synchronization Panel}

Synchronization panel is automatic Electrical device which synchronizes various generators. It is better to use a synchronization panel which must have properties like automatic and manual synchronization, load sharing at generators according to the power; it should automatically start and stop generators according to the load, automatically balance work hours (co-aging) etc. For this proposed solution refer synchronization panel is TEKSAN. Generators made by company which produces generators and synchronization panels. Model: TJPS10 Synchro- 


\section{LOAD FLOW REPORT}

\begin{tabular}{|c|c|c|c|c|c|c|c|c|c|c|c|c|c|c|}
\hline \multicolumn{3}{|c|}{ Bus } & \multicolumn{2}{|c|}{ Volinge } & \multicolumn{2}{|c|}{ Generation } & \multicolumn{2}{|c|}{ load } & \multicolumn{5}{|c|}{ Load Flow } & \multirow{2}{*}{$\frac{X F M R}{x \text { TQ }}$} \\
\hline & $\mathbb{D}$ & $w$ & \$ Maq & Ane. & MW & Lbur & MW & Mtve & $\mathbb{D}$ & $M W$ & Whe & And & XPF & \\
\hline \multirow{3}{*}{\multicolumn{2}{|c|}{ “Basl }} & 0.400 & 100.000 & 0.0 & 0.124 & 0.093 & 0 & 0 & Das2 & 0.049 & 0037 & 883 & 80.0 & \\
\hline & & & & & & & & & Buss & 0.020 & 0015 & 36.4 & 80.0 & \\
\hline & & & & & & & & & Buse & $0.05 s$ & 00041 & 98.7 & 80.0 & \\
\hline \multirow{2}{*}{\multicolumn{2}{|c|}{ Das2 }} & 0.400 & 99.477 & 0.0 & 0 & 0 & 0.014 & 0010 & Busl & .0 .049 & .0036 & 883 & 80.0 & \\
\hline & & & & & & & & & Des3 & 0.035 & 0026 & 629 & 80.0 & \\
\hline \multirow{2}{*}{\multicolumn{2}{|c|}{ Dus3 }} & 0.400 & 99.317 & 0.0 & 0 & 0 & 0.020 & 0015 & Bus2 & .0 .035 & .0026 & 629 & 80.0 & \\
\hline & & & & & & & & & Bust & 0.015 & 0011 & 26.4 & 80.0 & \\
\hline Dest & & 0.400 & 99.227 & 0.0 & 0 & 0 & 0.015 & 0.011 & Bxs3 & .0 .015 & .0011 & 26.4 & 80.0 & \\
\hline Duss & & 0.400 & 99.877 & 0.0 & 0 & 0 & 0020 & 0.015 & Dusl & .0 .020 & .0015 & 36.4 & 80.0 & \\
\hline \multirow{3}{*}{\multicolumn{2}{|c|}{ Bus? }} & 0.400 & 99.063 & 0.0 & 0 & 0 & 0 & 0 & Buse & .0 .032 & .0024 & 589 & 80.0 & \\
\hline & & & & & & & & & Bus8 & 0.019 & 0015 & 35.4 & 80.0 & \\
\hline & & & & & & & & & Das 12 & 0.013 & 0010 & $23 \mathrm{~s}$ & 80.0 & \\
\hline \multirow{2}{*}{\multicolumn{2}{|c|}{ Bus8 }} & 0.400 & 98.934 & 0.0 & 0 & 0 & 0 & 0 & Bas? & .0 .019 & .0015 & 35.4 & 80.0 & \\
\hline & & & & & & & & & Dus11 & 0.019 & 0.015 & 35.4 & 80.0 & \\
\hline \multirow{3}{*}{\multicolumn{2}{|c|}{ Bus }} & 0.400 & 99.499 & 0.0 & 0 & 0 & 0 & 0 & Bas? & 0.032 & 0024 & 589 & 80.0 & \\
\hline & & & & & & & & & Dus 10 & 0.022 & 0016 & 398 & 80.0 & \\
\hline & & & & & & & & & Bus1 & -0.054 & .0041 & 98.7 & 80.0 & \\
\hline Dus 10 & & 0.400 & 99.364 & 0.0 & 0 & 0 & 0.022 & 0016 & Buse & -0.022 & .0016 & 39.8 & 80.0 & \\
\hline Das11 & & 0.400 & 98.658 & 0.0 & 0 & 0 & 0.019 & 0.015 & Bas8 & .0 .019 & .0015 & 35.4 & 80.0 & \\
\hline Bas 12 & & 0.400 & 98975 & 0.0 & 0 & 0 & 0.013 & 0010 & Bas? & .0 .013 & .0010 & 23.5 & 80.0 & \\
\hline
\end{tabular}

Figure 6. Load flow report with aluminum conductor.

nization Panel.

\subsection{Cables Price \& Length Calculation}

For this solution proposed, there is requirement to install some new cables of different gauge at different locations as shown in the Figure 9. Cables at some locations are already installed. The length, gauge and location for the new cables are shown in the Table 12.

For this solution, cables of two different gauges i.e. $240 \mathrm{~mm}^{2}$ and $400 \mathrm{~mm}^{2}$ have to be installed. The total length of $240 \mathrm{~mm}^{2}$ is 125 meters, which includes 33 meters from A Block to M Block and 92 meters from S Block to P Block. The total length of $400 \mathrm{~mm}^{2}$ is 195 meters which includes 105 meters from B Block to A Block and 90 meters from B Block to S Block. The cost comparison for these lengths of 3 \& half core non-armored copper, aluminum and copper aluminum conductor given below in Tables 13-15.

\subsection{Total Cost for the Solution}

For the proposed solution we have to put all the generators at one place and then synchronize them through a synchronization panel. Then we have to install some cables that are mentioned above. The total cost comparison for this solution including panel and cable cost is given below in the Table 16.

Hence the total cost for this solution is Rs. 4.13 million Rs. 


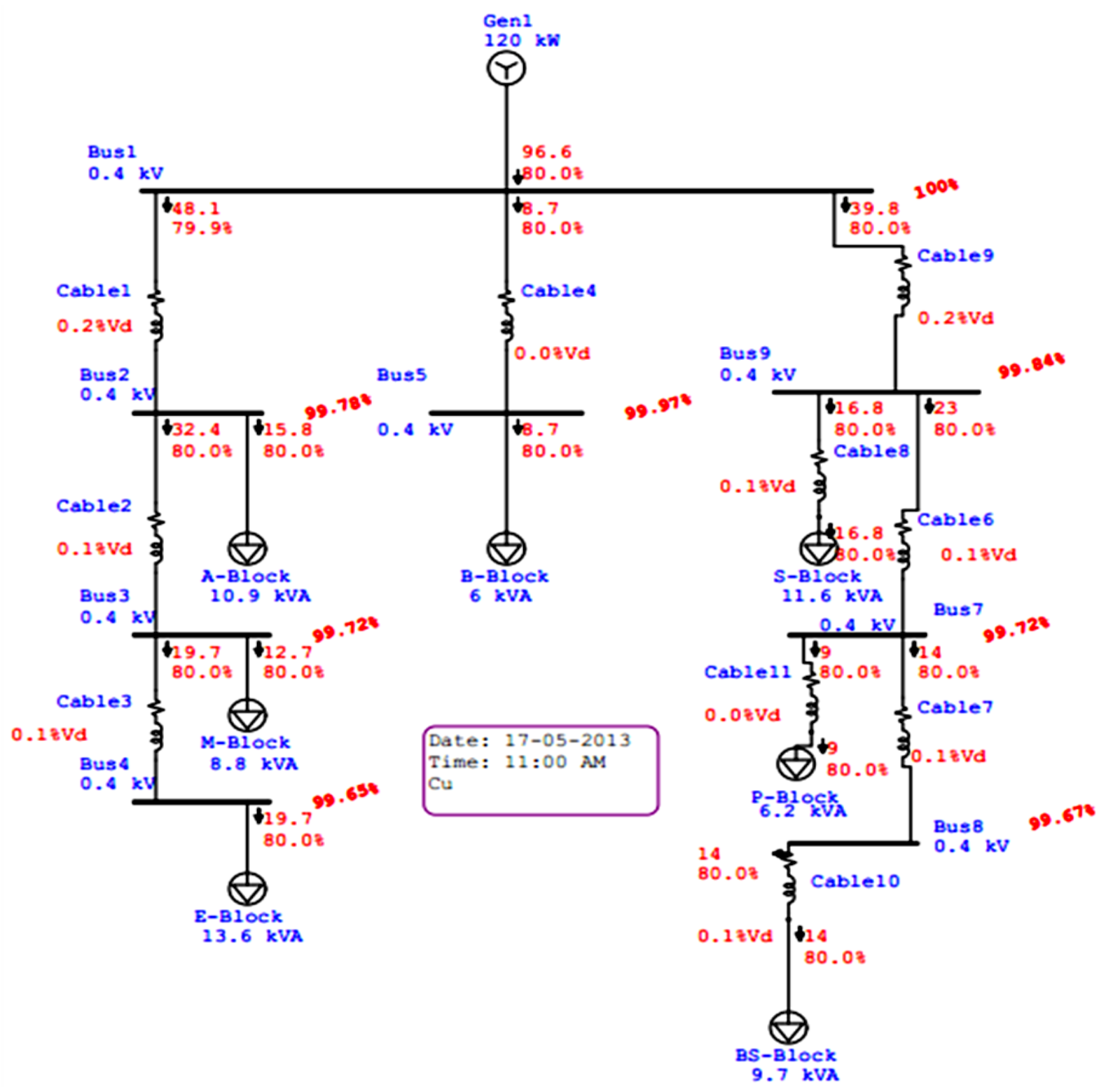

Figure 7. E-TAP model with copper conductor.

Table 12. Cable length required.

\begin{tabular}{cccc}
\hline Cable & Gauge & Location & Length \\
\hline 1 & $400 \mathrm{~mm}^{2}$ & From B to A Block & $105 \mathrm{~m}$ \\
2 & $240 \mathrm{~mm}^{2}$ & From A to M Block & $33 \mathrm{~m}$ \\
3 & $400 \mathrm{~mm}^{2}$ & From B to S Block & $90 \mathrm{~m}$ \\
4 & $240 \mathrm{~mm}^{2}$ & From S to P Block & $92 \mathrm{~m}$ \\
\hline
\end{tabular}

Table 13. Price for copper conductor.

\begin{tabular}{|c|c|c|c|c|c|}
\hline Cable & Specification & Current rating & Length required & Price/meter (Rs.) & Total price (Rs.) \\
\hline $240 \mathrm{~mm}^{2}$ & 3 \& half core cable & 410 & 125 & 9000 & $1,125,000$ \\
\hline $400 \mathrm{~mm}^{2}$ & 3 \& half core cable & 545 & 195 & 14,540 & $2,835,300$ \\
\hline Grand total & & & Rs. 3.96 million & & \\
\hline
\end{tabular}




\section{LOAD FLOW REPORT}

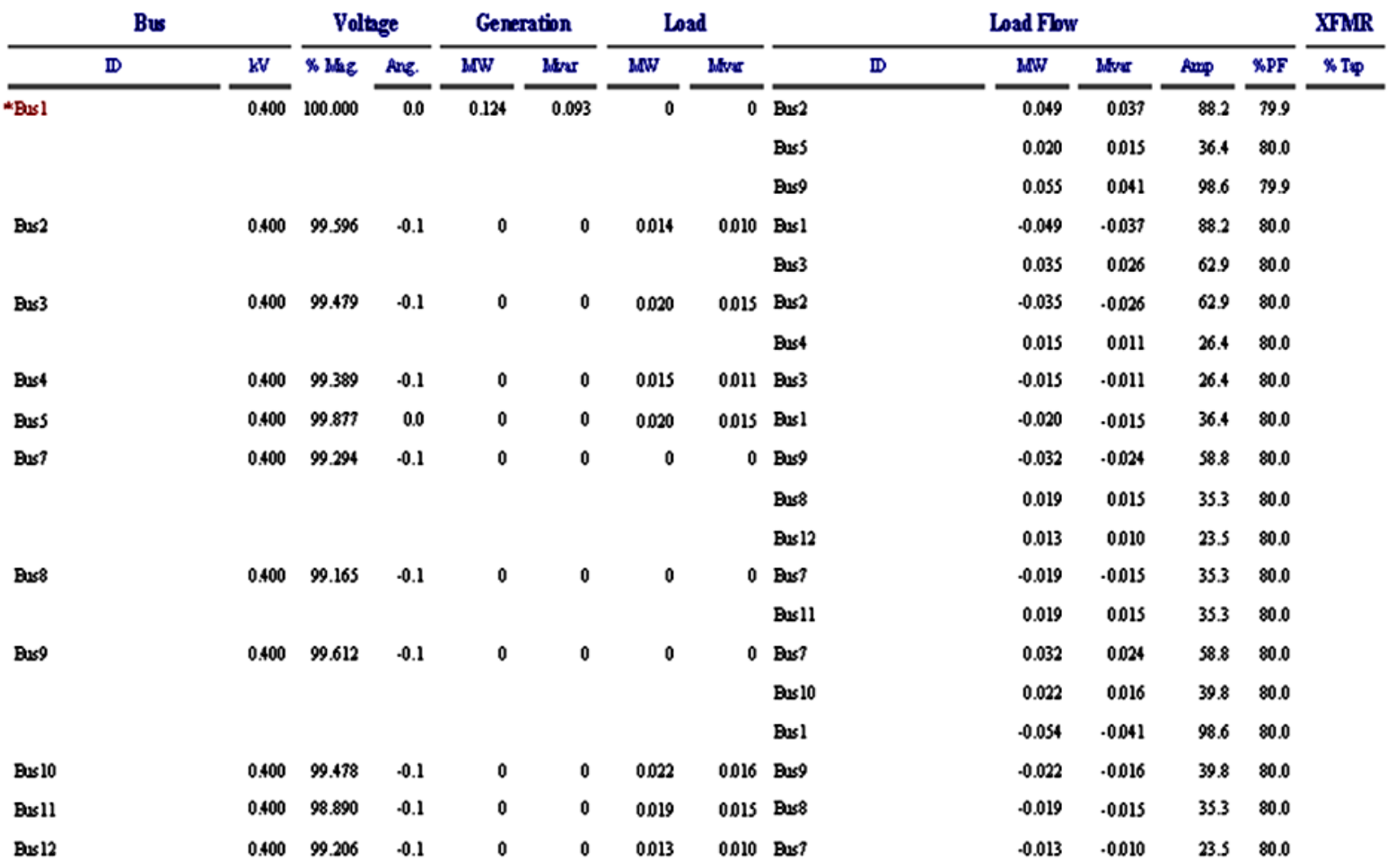

Figure 8. Load flow report with copper conductor.

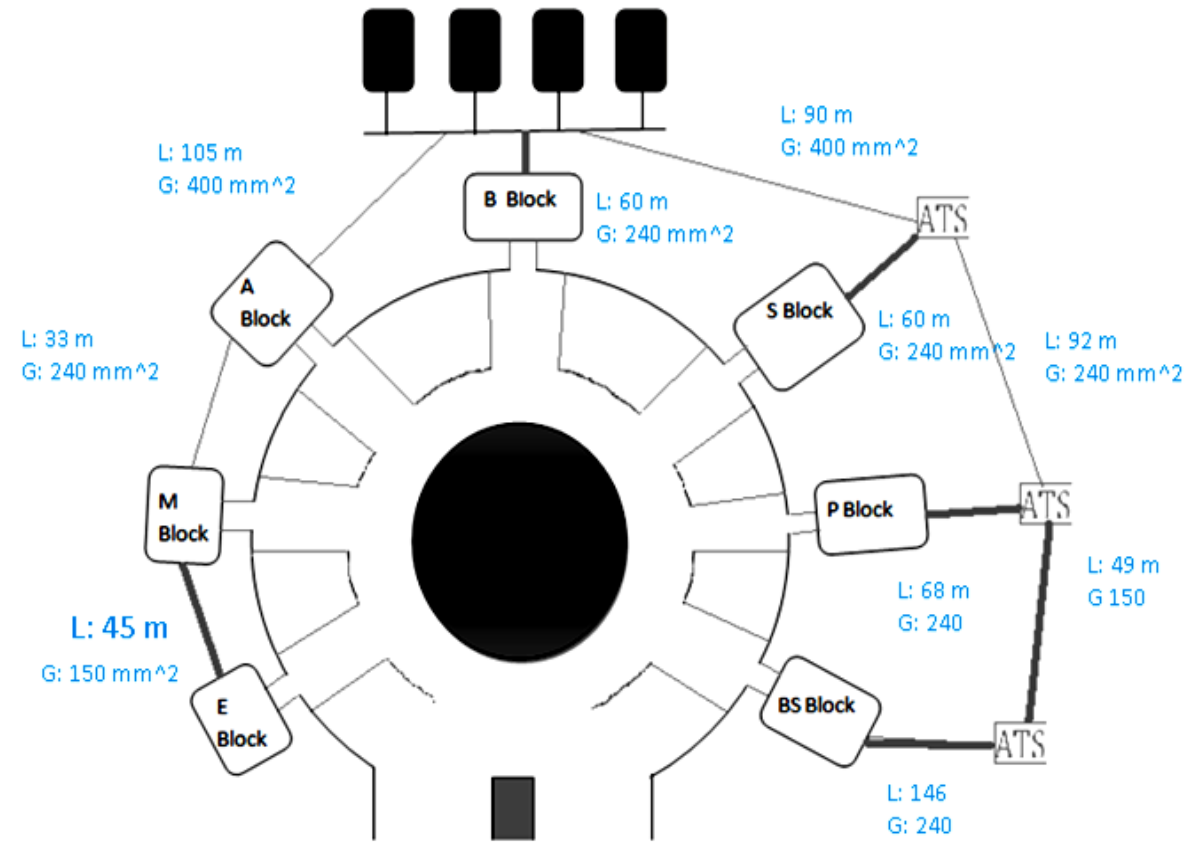

Figure 9. Proposed model for synchronized operation. 


\subsection{Pay Back Period}

As have been seen from the real time calculations that diesel cost can be save every month in a good manner. Adding all the diesel savings and approximated savings for coming months can be helpful to obtain the payback period. Total saving in current year have been shown in Table 17.

The approximated savings in the up-coming months are estimated below in Table 18.

It is clear from calculations that 18 months are required to compensate these costs. So if Synchronized net

\section{Table 14. Price for aluminum conductor.}

\begin{tabular}{cccccc}
\hline Cable & Specification & Current rating & Length required & Price/meter (Rs.) & Total price (Rs.) \\
\hline $240 \mathrm{~mm}^{2}$ & 3 \& half core cable & 361 & 125 & 1470 & 2400 \\
$400 \mathrm{~mm}^{2}$ & 3 and half core cable & 490 & 195 & 468,000 \\
Grand total & & & Rs. 6.51 Lac & \\
\hline
\end{tabular}

Table 15. Price for copper aluminum conductor.

\begin{tabular}{cccc}
\hline Cable & Conductor & Length required & \multicolumn{2}{c}{$\begin{array}{c}\text { Cost/meter } \\
\text { (Rs.) }\end{array}$} & $\begin{array}{c}\text { Total price } \\
\text { (Rs.) }\end{array}$ & 2400 & 300,000 \\
$400 \mathrm{~mm}^{2}$ & Aluminum & 125 & 14,540 \\
$400 \mathrm{~mm}^{2}$ & Copper & 195 & $2,835,300$ \\
Grand total & & & 3.13 million Rs. \\
\hline
\end{tabular}

Table 16. Total cost.

\begin{tabular}{cccc}
\hline Cable & Equipment & Equipment price (Rs.) & Grand total (Rs.) \\
\hline 1 & Synchronization panel & $1,000,000$ & Rs. 4.13 million \\
\hline
\end{tabular}

Table 17. Estimated savings.

\begin{tabular}{ccc}
\hline Sr. \# & Saving in this month & Grand total \\
March & 441,575 & 104,075 \\
April & 239,400 & Rs. 1.2 million \\
May & 199,500 & 252,000 \\
June & July & 2500 \\
\hline
\end{tabular}

Table 18. Approximated savings.

\begin{tabular}{ccc}
\hline Sr. \# & Savings & Grand total \\
\hline August (2013) & 200,000 \\
September (2013) & 250,000 \\
October (2013) & 300,000 \\
November (2013) & 300,000 \\
December (2013) & 300,000 \\
January (2014) & 300,000 \\
February (2014) & 300,000 \\
March (2014) & 300,000 \\
April (2014) & 100,000 \\
May (2014) & 200,000 \\
June (2014) & 100,000 \\
July (2014) & 200,000 \\
August (2014) & 150,000 \\
\hline
\end{tabular}


work is being installed in December 2013, the amount can be getting back in June 2015. Hence the payback period is approximately 18 months.

\section{Conclusion}

From the preceding analysis one can conclude that implementing parallel Synchronization technique can bring advantages in the form of power and cost saving. Total cost of the solution is 4.13 million and total annual expenses of old system is 3708100 Rs. Total approximated cost saving in 18 months is 4236550 Rs. with average monthly saving is 235363.9 Rs. Hence payback period of this solution is 18 months.

\section{References}

[1] http://kbreee.blogspot.com/2013/07/parallel-operation-of-two-alternators.html

[2] ADB (2010) Islamic Republic of Pakistan: Rental Power Review. Asian Development Bank.

[3] Ahmad, M.B. (2010) Worsening Gas Crisis.

[4] Alternative Energy Development Board (2011) Power Sector Situation in Pakistan.

[5] Report Prepared by Alternative Energy Development Board in Collaboration with Deutsche Gesellschaftfür Technische Zusammenarbelt (GTZ) GmbH, Islamabad.

[6] http://www.lesco.gov.pk/CustomerServices/3000063.asp

[7] http://www.usbr.gov/power/data/fist/fist1_4/vol1-4.pdf

[8] Asif, M. (2011) Energy Crisis in Pakistan—Origins, Challenges and Sustainable Solutions. Oxford University Press, Karachi. 
Scientific Research Publishing (SCIRP) is one of the largest Open Access journal publishers. It is currently publishing more than 200 open access, online, peer-reviewed journals covering a wide range of academic disciplines. SCIRP serves the worldwide academic communities and contributes to the progress and application of science with its publication.

Other selected journals from SCIRP are listed as below. Submit your manuscript to us via either submit@scirp.org or Online Submission Portal.
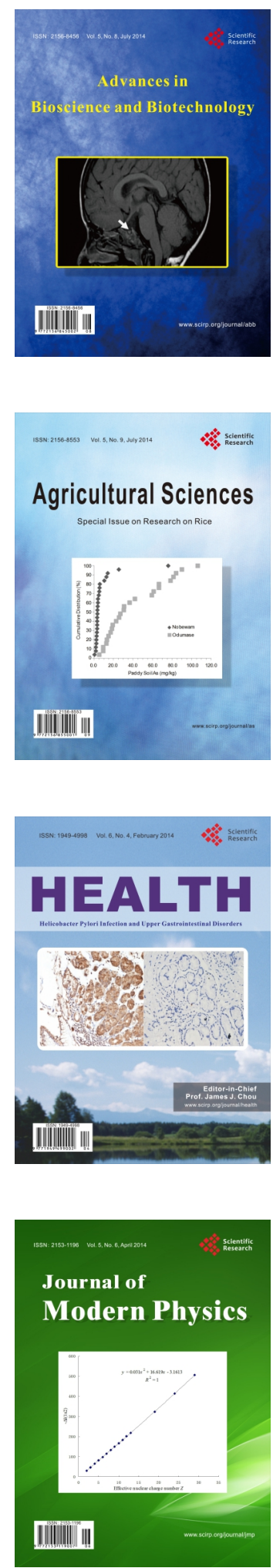
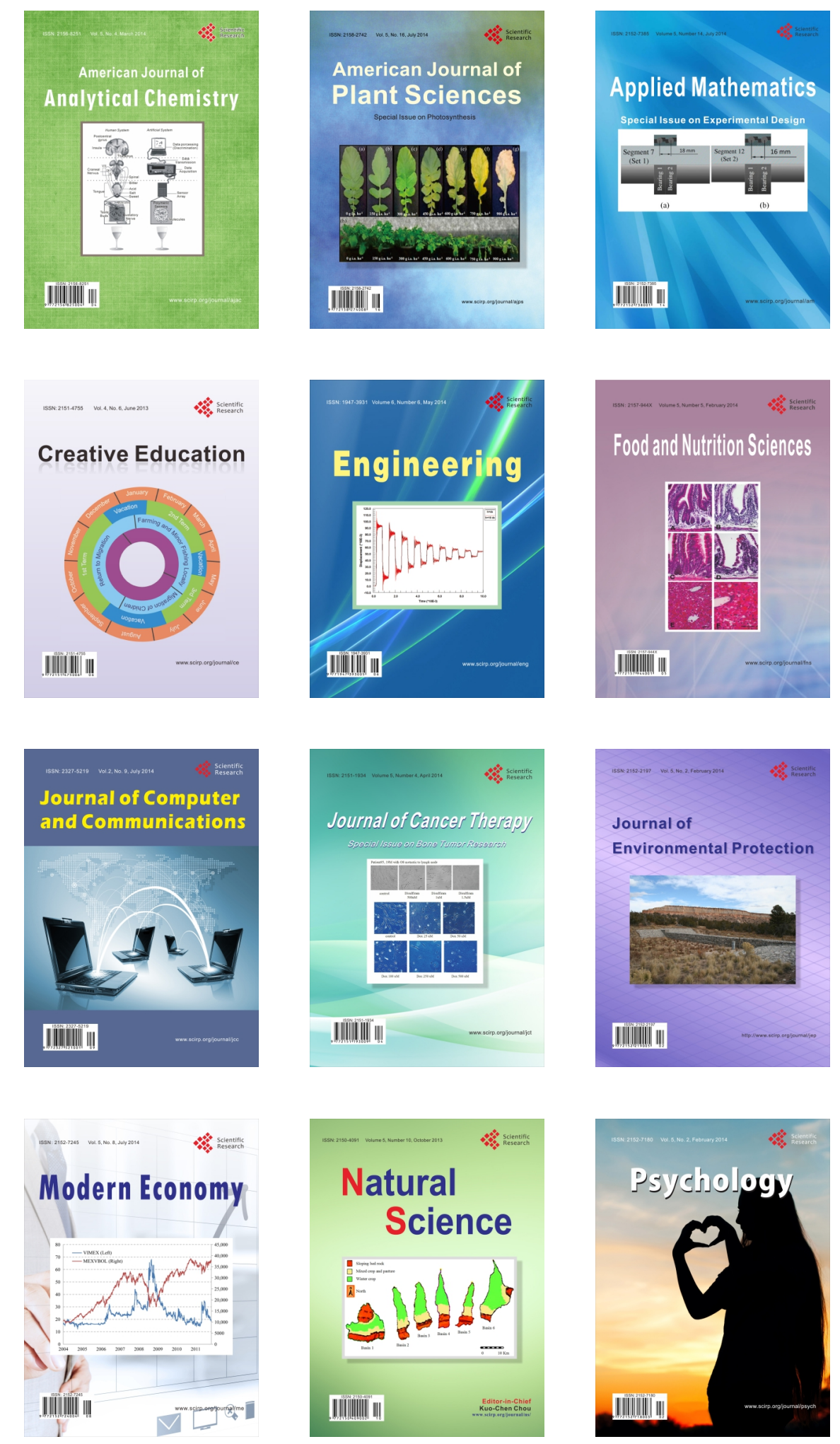